\title{
TOURISM AND STRATEGIC PLANNING: LEARNING FROM THE CHINESE PROVINCE OF HAINAN TO IMPROVE THE SYRIAN COASTAL REGION
}

\author{
BASHAR DAYOUB ${ }^{1,2}$, PEIFENG YANG $^{1}$, ALAA DAYOUB $^{3}$, TAREK BARAKAT $^{2} \&$ HE LI $^{1}$ \\ ${ }^{1}$ College of Architecture and Urban Planning/Key Laboratory of New Technology for Construction of Cities in \\ Mountain Areas, Chongqing University, China \\ ${ }^{2}$ Faculty of Architectural Engineering, Tishreen University, Syria \\ ${ }^{3}$ College of Economic and Business Administration, Chongqing University, China
}

\begin{abstract}
This paper is an analytical study of tourism plans of China's Hainan Province and the Syrian coastal region before the Syrian war commenced in 2011. It compares the two types of tourism (in the Mediterranean and the Asia Pacific) and concludes with an integrated model of successful regional tourism. The focus is on strategic plans of the last two decades and how they facilitate tourism, specifically, how strategic plans can be translated into sustainable tourism development projects in both regions. The strategic plan in the Chinese case considers environmental, economic, institutional, and social characteristics of tourism development, which determines the necessary infrastructure and environment for the further development of tourism. This is contrasted with the absence of such a strategy in the case of Syria. Data were drawn from in-depth interviews, field observations, and document analysis. Qualitative research techniques were used to analyze the available data and to form a detailed description of the past, present, and future potential for tourism in the two regions. The study measures transportation, land use/land cover patterns, tourism and tourism development, urban development, and strategic plans. It applied the lessons learned from Chinese tourism innovations in Hainan to propose an executive plan for sustainable tourism development in the Syrian coastal region once the present war has ended. This requires the active participation of all relevant stakeholders from almost every domain despite differing interests. It further requires improving the integration of three separate developmental factors (social, environmental, and economic) as complementary rather than conflicting elements.
\end{abstract}

Keywords: Syrian coastal region, Syria, Hainan province, China, strategic plans, development, policy, planning.

\section{INTRODUCTION}

Syria is a clear case of how and why the tourism destination could lose competitiveness along the years. After years of strategic myopia, there is a need to revisit Syria's tourism strategy that formalizes its vision and shows the key factors that can also be used in order to regain ground.

The research highlights Syria's tourism strategies and explains how a new approach should make the Syrian destination in the coastal region able to successfully compete in the tourism market benefiting from the Chinese experience in Hainan. The purpose of the research is to illustrate and to discuss the recent Strategic plans for the tourism development in Syrian coastal region in the period before the Syrian war in 2011.

The destination competitiveness theories argued that the presence of artistic, natural and historical attractions is a necessary but not enough condition to create unique experiences. In the absence of a clear tourism strategy that determines the desired positioning (regarding the wealth of attractions, the resources available, the interests of community and the desired target of customers), the supply tends to focus on a few things that are already known to the public in general, with negative effects on accessibility and the quality of the visit experience [2]. 
Traditionally Syria has known a fragmented, myopic and general approach to destination, with scanty coordination between private and public-sector stakeholders and sometimes lack coordination between local and central government. Hence, this paper has the possibility to offer a primary evaluation of the Syrian strategic plan in the coastal region that would affect the destination's ability to satisfy and attract its customers from among potential tourists. The originality of the paper is twofold: first, Investigating and analyzing the strategic planning of tourism in both cases - Syrian coastal region and Chinese province of Hainan - second, learning from the Chinese tourist experience in Hainan province how to improve and develop tourist reality in the Syrian coastal region at international and national level.

Through some references to literature, the research introduces consideration of some main weaknesses of Syrian tourism development in the coastal region and proceeds with the illustration of the Syrian Strategic Plans in the coastal region. After a description of the Chinese tourism plans in Hainan province, used as a benchmark, the following discussion explores limitations and advantages of the successful strategic planning and illustrates some issues for further research. The study should, therefore, contribute to specific research on the importance of proper strategic planning in enhancing the competitiveness of the tourist destination from a sustainable tourism perspective.

\section{RESEARCH PROBLEM AND AIM}

In its quest for tourism development, Syria suffers from many serious problems. At the current stage, the main problems in the tourism development are the war, weak positioning in the international market, undeveloped infrastructure, the absence of sustainability and the training problem. Solving these challenges will help Syria to create a further dynamic tourism atmosphere and enter the world market with its special product in the post-war period [5].

While the Syrian coastal region has excellent potential to compete in the tourism industry (culture, climate, history, coastline, opportunities for investment due to relatively cheap labor and land compared to China), the Syrian coastal region has not been recognized as a popular tourist destination. The problem can be summed up as such: The Syrian coastal region is not a popular regional tourist destination considering all the potentials and assets it has. So, the Syrian Coastal Region could be a popular tourist destination with its potentials, while Hainan, China's advanced and successful position as a "definite" tourist destination. The research will try to learn from Chinese experience in Hainan to improve the Syrian coastal region.

\section{LITERATURE REVIEW}

Strategic planning for tourism is essential for product positioning, demand management and image creation[6]. However, tourism is a complex product that has been created as a compound for many key inputs. The final product should be planned taking into account the distinguishing characteristics of several factors, by supporting the demand for tourism and involving both private and public institutions in providing the services required to market[2]. In order to assure that tourism provides success, benefits and sustainability, the destination must be planned, organized, led and controlled[7].

The critical success drivers of the destination's competitiveness revolve around establishing an inspirational leadership and shared vision, guidelines, clear principles and values of sustainability, and strategic emphasis on people's factors such as political will, entrepreneurship, human resources development and community empowerment[8].

The impact of tourism and travel on the social and economic development of a nation can be substantial, opening it for capital trade and investment, business, creating entrepreneurial opportunities for the labour force and jobs, and enabling the protection of cultural and heritage value. To know its full impact, policy-makers, businesses, and governments need 
valid and dependable data on the influence of the tourism sector. It is possible to use this data to assess policies governing future industrial development and to offer acquaintance to guide sustainable and prosperous travel and tourism investment decisions [9].

Because of such considerations, tourism holds a prominent situation to create a favourable input to the sustainable development for local zones. It can be an effective tool for conservation and community development. Simultaneously, it can present challenges. If the tourism industry rules and standards have not been clear, they may have a negative impact on local sustainable development [11]. In order to obtain favourable results, it is essential to develop policies that take into account all the negative and positive impacts that tourism can have on the economic, social, environmental, and cultural development of a region. These policies should be created to take advantage of the positive opportunities it can bring and to minimize adverse effects.

Planning is widely seen as crucial in the development and management of successful tourism. It must be based on the principle of large-scale tourism development at the national and regional levels [13]-[14]. Since the benefits of planning can only be achieved if accompanied by an implementation plan, experts suggest that implementation is given significant consideration during the planning process [13], [15]-[20]. Ideally, the plan will be implemented as designed but, in practice, the planners often must deal with the fact that their initial choices were inaccurate and that they must now balance between pragmatism and idealism. These situations create a gap between planning and implementation which can cause the ultimate fail of tourism plans. For example, studies record the failure of tourism development plans due to a broad swathe of reasons including the lack of analytical details, incorrect assumptions about control over land use[19], the fail of central planning created by the shortage of community participation[22], and mismatches between local possibilities and central planning[23].

In this study, the distinction between tourism planning and urban planning may be determined by how the nature of tourism differs from that of community development, physical (infrastructure and facility) planning, and land use planning. Tourism planning usually focuses on the interests of specific groups in the population, particularly those in the private sector like tourism corporations, while urban planning usually seeks to serve the interests of broader society. Tourism planning often is focused more on the facilities and infrastructure that serve tourists such as associated leisure and hospitality sectors. Urban planning is generally more inclusive in its field, trying to pay attention to all the fundamental sides of quality of life and community development, although this varies from one location to another. Moreover, while urban planning is a basic social necessity, essential for the control of development and property values, tourism planning is not seen as a fundamental public necessity, thus voluntary cooperation is often less critical for public discussion [24]. George Friedman summarizes "the fundamental principle of strategic planning: "hope for the best, plan for the worst" [25].

In this paper, the Chinese Strategic Plan in Hainan province will be described in order to have a basis for comparison with the Syrian Strategic Plan in the coastal region.

\section{CASE STUDIES}

\subsection{Syrian coastal region}

Syria is located on the eastern coast of the Mediterranean Sea and has marine boundaries with Lebanon, Cyprus, and Turkey. Syria is divided into 14 governorates, two of which are located along the coast, namely Lattakia $\left(2,437 \mathrm{~km}^{2}\right)$ and Tartous $\left(2,193 \mathrm{~km}^{2}\right)$. The coastline 
of Syria is $183 \mathrm{~km}$ long. The Syrian coast also features cities, villages, historical sites, beaches, forests, mountains, and lakes. Furthermore, Syria created an Exclusive Economic Zone [26]. In the past century, the coast of Syrian saw the development of large naval facilities including a commercial seaport in Latakia, a commercial seaport and oil terminal in Tartous, and the oil port of Banias. Nevertheless, there are a few human marine activities in the region, particularly along the northern coast of Syria, and there is no evidence of a specific policy designed to launch a new wave of industrialization in the coastal region [27].

\subsubsection{Transportation}

A major highway links Latakia with Aleppo and has been supplemented by the completion of a railway line, for both passengers and freight, to Homs which supports two daily connections to Aleppo and one weekly run to Damascus via Tartous. Unfortunately, most of these trains stopped running because of the war. The airport is located 25 kilometres south of Latakia and was serving as a national and regional airport with regular flights to Jeddah, Riyadh Sharjah and Cairo. The Port of Latakia is also a crucial link for six organized cruises between Alexandria, Izmir, and Beirut as well as irregular ferry services to Cyprus.

\subsubsection{Land use/land cover patterns}

Data from field surveys, previous thematic maps, and satellite imagery indicates that the areas of Syria coastal have a variety of morphological characteristics. On the coastal plain, at lower altitudes, land use is characterized by intensive crop farming and tree ranches (specifically citrus and olive).

\subsubsection{Tourism and tourism development}

The Syrian coast, which stretches between its borders with Turkey and Lebanon, consists of $183 \mathrm{~km}$ of beach, green mountains with foothills of pine and oak trees, and numerous capes and bays. Along the western slopes of the coastal mountains are scattered villages and cultural sites, such as Slenfeh, Kassab, Wadi Al Oyoon, and Safita, that are often taken advantage of for recreational summer tourism. Before the Syrian civil war, improvements in land transportation and service infrastructure in the coastal region made it an attractive destination for mountain and beach summer recreation. Tourists who drove from inland Syria or other Arab countries and also included Syrian expatriate tourists, and European tour groups were often interested in visiting archaeological and heritage areas[30].

Before 2011, an average of 868,830 tourists (domestic, regional, and international) visited the region annually, constituting almost $16 \%$ of the total number of tourists in Syria. According to 2008 data (Ministry of Tourism in The Syrian Arab Republic 2008), the Syrian coast was visited by a huge number of tourists from all Syrian governorates. The Syrian Ministry of Tourism (before the present war) was aiming to double the number of tourists over the next ten years to $1,600,000$ (a $15 \%$ per annum increase in tourist numbers) and similarly increase tourism activity days. The investment will be provided to support the increase in demand in the form of employment programs that ensure smooth operations during tourist seasons areas.

Beach tourist resorts already occupy vast areas of the coastline, causing direct and indirect pressures on the coastal and marine environment. The mountain tourism has contributed to deforestation for construction and other services. The diversity of tourist destinations in the Syrian coastal region range from archaeological, historical, and cultural attractions (including religious shrines and museums) to beach and mountain tourism, ecotourism, nature reserves, and leisure tourism.

Operational Plan of the Ministry of Tourism to develop tourism in the coastal region: 
1. Focus on efforts of official promotions and marketing for tourism attractions with the necessary funds.

2. Consider untapped beaches for integrated tourism development.

3. Support legislation and regulations to establish tourism products and activities. These include tourist boats and floating restaurants on the beaches, various marine sports (including diving and sailing), tours of forests and natural reserves, presentations and concerts at archaeological sites, developing improved connections between coastal and mountainous areas (e.g., by cable car), and the promotion of mountain sports.

4. Activate and support domestic tourism by encouraging the establishment of furnished apartments, chalets, and hotels of grades appropriate to the desired type of tourist.

Efforts should have expanded to develop an integrated action in the coastal tourism policy to encourage the overall development of sustainable tourism. This includes the development of standards and guidelines for environmental tourism, local development schemes, giving support like data and expertise for sustainable tourism development, and support mechanisms to promote adequate labeling of tourist services, products, and accommodation [31].

\subsubsection{Urban development}

The Syrian coastal region faces serious problems due to the density of land-use and conflicting demands for use, which are often harmful to the natural environment. Other problems involve pressure from growing economic and urban growth, including tourism projects and cities, that has led to physical alterations from the levelling, dumping, and dredging of rock and earth, as well as construction and concretization work. To date, almost a third of the length of the coastline has been changed through structures such as hotels, restaurants and cabanas, industrial facilities, and oil plants (such as the power plant in Banias located on the coast) and the commercial ports, as well as expanded cornices at the seafronts of these four coastal cities (Latakia, Jableh, Banias and Tartous) [31]. The coastline is under threat in some areas because of coastal erosion caused by engineering work and development projects that did not adequately consider coastal processes and dynamics. A rising sea level caused by climate change may increase this corrosion effect in the future [32].

\subsubsection{Strategic plans}

Weak public participation in policy-making as well as academic and social insensitivity to the issues of coastal tourism results in the continued absence of an integrated strategic norm to the spatial planning of the coastal zone. Limited credible statistics and scientific data combined with inadequate diagnosis of problems and identification has weakened planning in general and tourism planning in particular. Especially in the field of tourism, there is a low level of awareness about the environmental factors by the administration and public. Evidence of this is seen in the high degree of pollution Syria faces, which led to the undervaluation of the coastal region. [26]

International support and regional cooperation on coastal and marine issues under the Barcelona Convention and its Protocols and other relevant structures address these matters. The Syrian participation in this concern will be a substantial contribution to the collective efforts of the Mediterranean countries to safeguard the future of their sea and to enable Syria to better meet its obligations arising from the Protocols of the Barcelona Convention [31]. This document included preparations for fulfilment (at a national level) of the requirements and provisions of the seventh protocol of ICZM in the Barcelona Convention framework; it 
represents a vital milestone in the history of the action plan for the Mediterranean Sea. It also complements a variety of other protocols for the preservation of the Mediterranean region and its marine environment. This will improve the capabilities of the Mediterranean countries to protect and manage their coastal areas, and for dealing with emerging coastal environmental challenges such as climate change.

The Protocol of the Barcelona Convention is a unique legal instrument for integrated coastal zone management in the international community as a whole; it could serve as a model for other regional seas in the world. This is detailed in "Towards a Strategy for Syria's Coast" found in "On integrated Coastal Zone Management". In 2008, a summarized policy of ICZM ("Coast 2025") was developed within the framework of the Soil Moisture Active Passive (SMAP) program as a first step for the Syria coast pursuing the strategy of sustainable development [26].

This statement of the Syrian vision for the coastal area declares, "The future of Syria's coast visualizes it as a safe, clean, healthy and attractive coast that provides the best potential quality of life for future and current generations, where people can enjoy economic prosperity that also ensures good environmental, social, cultural and healthcare conditions".

The rising rate of marine and coastal pollution resulting from urban and industrial development drove Syria in 1988 to the upgrade of its CAMP (Coastal Area Management Program). This movement toward integrated coastal zone management, supported by the Syrian authorities, the United Nations Environment Program (UNEP), and the Mediterranean Action Plan (MAP), focused on the domestic coastal sector. By 1994, the program concluded and produced a general overview of the major results of the coastal area of Syria [26]:

- Policy suggestions for the preservation of freshwater resources, including the creation of health protection areas around water works and appropriate waste management technologies and practices.

- Some immediate measures were proposed for dealing with illegal construction, the protection of wetlands and the coastal sector, and the extraction of sand from dunes.

- The formulation of land use planning policies, including both urban development and a detailed land-use survey.

- Established an inter-ministerial high-level commission for coastal management to ensure the integration of development decisions and policies.

- Developed a plan for the protection of fresh water and an integrated program for the management of coastal resources.

- Progressive implementation of structural measures for solid and liquid waste management, with consideration given for huge urban settlements.

\subsection{Hainan}

Located in Southeast Asia along the Pacific coast, China is the fourth largest country in the world, after Russia, Canada, and the USA[34]. Hainan, the smallest $\left(33,920 \mathrm{~km}^{2}\right)$ and southernmost province of China, is an island located in the South China Sea. It is separated from Guangdong's Leizhou Peninsula to the north by the narrow and shallow Qiongzhou Strait. There is a total of ten counties and ten major cities on the Island. Sanya is a popularly known tourist destination on the southern shore while Haikou is the capital located on the north coast. Other major cities are Wanning, Qionghai, Danzhou, and Wenchang. 


\subsubsection{Transportation}

- Highway: The total length of the Hainan highway system is more than $17,000 \mathrm{~km}$, including a national highway along the island's coast linking each harbor and main city. The 12th Five-Year Plan (2011-2015) approved the construction of $400 \mathrm{~km}$ of highway at a total cost of RMB 60 billion, of which the main project was the construction of a national level highway linking the east and west sides of the island directly[36].

- Railway: There are five railway routes (including a high-speed train which started operations in 2004) from Haikou to other cities which include: Sanya to Beijing West, Haikou to Xi'an, Haikou to Chengdu East, Haikou to Changsha, and Haikou to Shanghai South. The journey from Sanya to Haikou is $308 \mathrm{~km}$ and takes about 2 hours[37].

- Qiongzhou Strait Bridge: As of 2018, all vehicles and trains traveling between the mainland and Hainan go by ferry across the Qiongzhou Strait, a 90-minute trip. Plans to create a bridge across the strait were included in the 12th Five-Year Plan. The project is scheduled to be completed by 2020 .

- Waterway: Hainan has 24 ports, of which Sanya, Haikou, Yangpu, and Basuo are the biggest. Shipping from the ports increased dramatically since 2011 and plans of the local government focused on developing the ports at Sanya, Yangpu, Basuo, and Haikou. The port at Sanya will be modified to receive cruise ships as well[38].

- Air: Sanya Phoenix Airport and Haikou Melan Airport, the only two airports on the island, are currently expanding capacity to increase their combined annual throughput from 20 million passengers to 50 million. These two airports are already working at more than $100 \%$ of their actual designed capacity.

4.2.2 Tourism-led land-use and environment changes in Hainan province

In most developing countries, tourism is usually an effective means of promoting the economic growth and the development in general of coastal zones. As Hainan is the most famous tourist destination and the most significant Special Economic Zone in China, it selected a tourism-led development pattern and has since achieved rapid growth of the economy. The significant shifts in land use have been from forestland to orchards and from farmland to construction land, i.e., areas allocated for buildings and installations. From 1991 to 2007 , forest land and farmland declined $15 \%$ and $29 \%$ respectively, while orchards and construction land grew $242 \%$ and $258 \%$. The shift from agricultural to construction land has occurred in the plains along the coastline, while most of the changes from forests to farmland have occurred in central areas of the island. The flourishing of tourism has not only led to increased demand for rapid urbanization and tourism infrastructure but has also considerably enhanced sales for tropical fruit products, explaining this increase in orchard usage [39].

Development stimulated by tourism has dramatically restructured patterns of land use, raising concerns about of landscape fragmentation, vegetation degeneration, coastal erosion, and the loss of arable farmland. Poorly planned tourism and land use has, to some extent, led to the destruction of the tourism resources in Sanya and the decline of its principle advantages which will limit the future of the sustainable development of tourism[39].

\subsubsection{Tourism and tourism development}

Often referred to as the "Oriental Hawaii," Hainan is a popular tourism destination in China. Haikou, located on the northern part, is the economic, political, cultural, and transportation center of Hainan province. Sanya, in the southernmost part, has established itself as the most 
popular tropical tourist city in China, thanks in part to its high concentration of internationally recognized resort hotels. In consideration of the economic importance of tourism and travel, the Hainan Provincial Government must make its utmost effort to nurture the industry in order to ensure its development in a sustainable manner. This will require precise control and monitoring by the government, and close cooperation between the private sector and the municipal authorities [40].

In Hainan province, the 12th Five-Year Plan (2011-2015) approved an extensive listing of projects for infrastructure and resort superstructure to include luxury hotels, shopping centers, cultural tourism projects, tourism facilities, and attractions including an underwater sea world and an artificial ski center. Many of these projects were completed by the end of the five-year period; all of them are expected to be operational by the year 2020 . The total cost of the 64 projects is 372.5 billion RMB[41].

During the period of the 12th Five-Year Plan, 15 major tourist areas and 63 hotels (fivestar and higher) were completed. This was to meet the current trend of tourism, along with the increasing demands by developers and investors. Hainan had more than 100 five-star or higher hotels at the end of this five-year period, making it one of the highest density tourist resorts in the world. It is notable that these developments included a strategy for sustainable tourism development. This featured well planned, coordinated, implemented, and substantial investments in training and education. Their purpose was to provide the necessary human resources to deal with demands for sustainable and efficient further growth, marketing, and promotion. This was accompanied by the conducting of in-depth promotion research for market diversification and to produce excellent products. [41]

Simultaneously, there is a combination of factors working in parallel to escalate regional tourism and build a regional tourism destination.

- $\quad$ First master plan (completed in 2002)

With the cooperation of the World Tourism Organization (UNWTO), the first Tourism Development Master Plan was completed in 2002. For most of the first decade of the $21 \mathrm{st}$ century, tourism development in Hainan was slow but tourism and investment accelerated rapidly after the Chinese State Council announced in December 2009 that Hainan Island would be upgraded to become an international tourism destination. By 2008, the Hainan Provincial Government had already updated their Master Plan, built much of the infrastructure needed for the first master new resorts, and attracted some of the leading tourism investors in Hainan. Many of those investors formed co-partnership agreements with international hotels companies' groups in order to operate the hotels and resorts[41].

- $\quad$ The staggering pace of development

A few years ago, the development speed became spectacular, especially regarding resorts, hotels, and infrastructure such as the Hainan's high-speed East Ring Intercity Rail Link. Presently, Hainan is prominently on the map of world tourism, and this is not expected to be changed for at least a decade.

- $\quad$ Tourism policy

Benefiting from the support of the central government, the provincial government of Hainan has worked to facilitate the development Hainan as an international tourist destination. Six 
strategies were included in the State Council declaration specifying Hainan's development as an international tourist destination[41].

1. Making Hainan a holiday tourist and world-class travel and leisure destination.

2. Developing the island into an essential platform for international economic cooperation and cultural exchanges.

3. Making Hainan a pioneer in tourism industry rehabilitation in China.

4. Improving Hainan as a service center in parallel with being a national, modern tropical agricultural center.

5. Creating a special demonstration area for ecological development in China.

6. Developing resources in the South China Sea.

\subsubsection{Urban development}

Since the start of market reform and the opening-up of development, and especially since the establishment of the province as an exclusive economic zone, Hainan has seen considerable progress in its economic and social development. There have been profound changes in the nature of its urban and rural areas, and significant improvement in living standards. This has marked the province's new stage of rapid development, the pace of which has been staggering over the last few years although infrastructure schemes such as Hainan's high-speed East Ring Intercity Rail Link is not expected to facilitate tourism for at least a decade. Hainan is already a strong presence in world tourism.

Over a period of 20 or more years, the strategic plan for rural and urban development provides a new paradigm of integrated rural, urban and national development. According to this plan, Hainan is divided into four principal regions: marine region, coastal region, adjacent agricultural region, and central highlands. It also identifies 4 urban and 21 rural planning areas. The general goal of this plan is to make a "harmonious Hainan" grounded in economic regeneration, rural and urban modernization, improved environment, and increased welfare [42].

\subsubsection{Strategic plans}

The "State Development's Opinion Regarding the Developing Hainan into an International Tourism Island 2010" Plan will take advantage of the pleasant climate and natural scenery of Hainan to position it as an international tourism hotspot by 2020. The plan concentrates on creating a globally renowned travel destination by speeding up the development of the tourism sector in Hainan and its broader service industry. It also calls for preserving and protecting the environment, in addition to balanced development through the process. By 2020, Hainan is expected to enjoy an improved and sophisticated service industry and an integrated infrastructure for fast and convenient travel between cities and attractions. Such developments will upgrade its international stature as a profitable travel destination. Further opening up of the tourism sector has also been planned, including visa exceptions and the introduction of tourism management using modernized marketing and sales from globally recognized travel agencies and hotel management groups [38].

Realizing the tourism potential of Hainan in coordinated long-term planning is crucial, especially regarding HR needs. A strategy for sustainable tourism development has been carefully planned and implemented. This plan will invest heavily in training and education to provide human resources to meet the growing demand. It will feature efficient and sustained marketing and promotions aimed at achieving market diversification and a unique product by focusing on utilizing in-depth market research[41].

The strategic plan has divided Hainan into six main function groups, as detailed below: 
- Northern Group: This exists around Haikou and focuses on various sectors such as media and culture, exhibitions and conferences, commercial and retail sales, insurance, finance, training, education, auto manufacturing, real estate, food processing, and pharmaceuticals.

- Western Group: The western part of Hainan focuses on building the technologyintensive industries and developing the harbor of the Yangpu economic development zone. There is a further focus on building up the central city of Danzhou on the western part of the island.

- Eastern Group: Qionghai and Waning focus on expanding tropical agriculture, coastal tourism, fishing, and processing. Meanwhile, Bo'ao becomes a desirable place for international conferences.

- Southern Group: This group around Sanya focuses on entertainment, hospitality, commercial, retail, and urban rehabilitation. There is more emphasis on promoting Sanya as a scenic attraction and eventually making it known around the world as a famous tropical coastline resort.

- Central Group: The interior region group focuses on balancing economic development with environmental preservation while developing cultural tourism, ethnic- and eco-tourism, forestry, and tropical agriculture.

- Ocean Group: This consists of Xisha, Nansha and Zhongsha islands and focuses on solidifying their position as a center for fishing and transportation, and for expanding the extraction, exploration, and processing of gas and oil resources in the marine areas [38].

This plan foresees travel and tourism will become the principle economic force in Hainan and produce large amounts of foreign exchange earnings. It will diversify Hainan's economy and encourage entrepreneurship, especially among medium- and small-sized enterprises. This will stimulate further investment and create large numbers of new, sustainable employment opportunities. Less widely recognized but hugely important is that this economic development will aid in the poverty alleviation and boost social development in the local communities.

The Hainan Island international tourism development strategy can be summarized as follows:

1. Increase efforts to develop a modern service industry, especially in real estate, tourism, logistics, media, offshore financial services, and travel insurance.

2. Impose strict environmental protection regulations and laws, aggressively push for saving energy, and improve pollution prevention and emissions reduction.

3. Promote seafood production and focus on the new tropical agriculture products (food crops, flowers, and tropical fruits).

4. Build an organic agricultural production center.

5. Accelerate the integration progress between rural and urban areas.

6. Optimize space planning and establish boundaries for the diverse functional areas of the cities.

7. Attract new residents and businesses by improving the cities' overall service capacity.

8. Increase infrastructure capabilities in transportation, internet services, and renewable technology.

9. Focus on minimizing the environmental impact associated with developing new industries like automobiles, medical research, luxury goods, marine technology, and information technology. 
10. Add Ukraine, Norway, Denmark, Finland, and Kazakhstan to the visa-free policy, increasing the number of countries which do not require a visa to visit Hainan to 26.

\section{THE RESEARCH ANALYSIS RESULTS}

As seen from the statistical data, websites, and interviews, the Syrian coastal region and Hainan share some key similarities, such as the geographical importance of the Mediterranean Sea and China Sea respectively. Regarding strategic improvements, Hainan Province already has extensive infrastructure and services which were established to turn Hainan into an international tourist destination by 2020, while the Syrian coastal region, suffering from a lack of adequate infrastructure and services, has experienced very slow development which obstacles its transformation as a regional tourism destination.

The administration managing tourism in Hainan province is more welcoming to investment and private industry than that of the Syrian coastal region. Evaluation policies built into Hainan's strategic planning procedures enable plans to be reviewed in order to analyze challenges and update plans accordingly, thus ensuring the plan is always on track to achieve its primary goals. By contrast, the Syrian coastal region has a distinct lack of administrative transparency or clear plans to obtain basic goals other than by long, tedious procedures and official forms which must be approved by the Minister of Tourism. The Chinese approach appears to be more understanding of the benefits of tourism and how it can bring investments and foreign capital to an area regardless of any negative impacts.

To sum up, the current differences in tourism between the Syrian coastal region and Hainan were presented in detail. These differences are due to three primary factors.

First, the Syrian coast is located in a small, poor country (Syria) while Hainan is in a large, rich one (China). This paper is not concerned with the differences in economic status but, rather, proposes to learn from the successful example of Hainan. This will allow the Syrian coastal region better strategic planning concerning its assets and potential for development and determine the funds required which will be appropriate for the economic situation of the Syrian coastal region.

Second, the different political situations encourage or restrict their development. Hainan Province possesses a dynamic atmosphere which inspires investment and development regardless of personal benefits and interests; that is, there is an interest in promoting the community and providing public benefits. On the contrary, for a long time, the Syrian coastal region has had an unhealthy and less dynamic atmosphere with the primary focus on personal welfare regardless of community and public benefits. Due to that attitude, investment and business growth have been limited. This development was further slowed by an inefficient and overbearing bureaucracy.

Third, location plays an important role in attracting both tourists and investment to a region. The Syrian coast is located in the Middle East which is the center of the most ancient civilizations in the world. But it also suffers from long-standing conflicts; this factor plays a significant role in attitudes toward business and tourism.

\section{DISCUSSIONS}

Tourism has been a positive experience in Hainan Province. The success in tourism planning in Hainan province is clearly due to a combination of factors, which can be summarized as:

- Tourism development includes many factors which are dependent upon government regulations, including those relating to the fabric of urban infrastructure, preservation of historical buildings and cultural areas, control of development 
demands, overcrowding, pollution, job safety, the provision for new technologies, and forms of work.

- The Government cannot resolve all problems. Stakeholders must be involved at all levels, leading to the development of consensus and the strengthening of partnerships between the public, private, and corporate sectors. In such partnerships, the municipal authorities should be a fundamental master because of the democratic mandate and their responsibilities, and, above all, because of their resources. However, it is essential that the municipality does not dominate the process. It should, ideally, act as a catalyst to bring others together and set an example for their cooperation.

- Tourism can encourage partnerships between the private and public sectors in the establishment of sustainable tourism facilities in rural and urban areas and can lead to improved activities and attractions linked to the heritage and culture of urban, historical, and natural areas. Such collaborations can be instrumental in reducing tourism-related traffic and promoting environmentally friendly modes of transportation.

- Tourism facilities can supply information concerning risks and appropriate behavior, develop projects to alleviate damage to the environment, promote education for sustainable development in universities and schools, introduce local tourism into the school curriculum, strengthen information networks, and conduct research on sustainable tourism.

- To achieve this, the tourist industry requires policy generating institutions, urban and regional planning, and participants from civil society working together to create long-term solutions in the field of tourism.

Objective criticism:

- The rapid development to turn Hainan into an international resort destination requires careful monitoring, without which there is a serious risk of growth in the largely uncontrolled supply side that could weaken the quality of travel and tourism in Hainan.

- The rich diversity of attractions and tourism resources, a highly attractive environment for investors, attracts interest from various stakeholders. However, this inevitably creates risks and highlights the significance of ongoing government funding and support for the optimal investment of the tourism resources.

- The growing significance of tourism and travel to Hainan province is unquestionable. Significant steps have been taken to develop the infrastructure that can support medium- to long-term growth. However, this growth needs to be managed carefully to guarantee development will be along sustainable lines.

- The reality that Hainan was a relatively unknown destination before 2009 but today offers a range of tourism products and unique holiday potential while being widely recognized as a safe destination, will unquestionably increase its appeal [43].

\section{CONCLUSIONS}

It is clear that there are substantial issues in applying the basics of sustainable tourism in the present economic environment in Syria. According to this regard, the resolution expressed in various policies must be put logically into practice.

There are about two series of issues that should be examined: 
1. Specific issues related to develop of tourism based on the principles of sustainable tourism;

2. Public developmental issues relating to the state of the society and country and to systemic solutions.

Among the general considerations, the first concerns the planning process and the issue of the coherence of government policy. Sustainable development policy, as applied to spatial planning and tourism, should be a synthesis of the policies of various government departments. For many people in the Syrian coastal region, the idea of planning itself brings to mind the memories of the long-held political system that had been perceived negatively. Thus, the role of properly developed development plans and strategies may not be properly appreciated. However, sustainable development depends on a long-term perspective and therefore requires a strategy that looks forward to 10 to 15 years.

The success of a tourism destination is decided by a wide range of factors. As part of a complex and dynamic industry, managers need to be continuously observing, analysing, and evaluating management strategies and tourism performance to guarantee the long-term of tourism for a destination. Strategic planning and continuous management adjustments can enable the progressive improvement and success of a sustainable tourism destination.

Frequent rotation of staff in ministerial posts and the rotation of government combinations led to the lack of coherence of strategic policies. This situation also extends to lower levels of state administration, including local governments.

\section{RECOMMENDATIONS}

Sustainable tourism has become a separate category of selective tourism. Destinations become a set of shared tourism services and products, involving the effective contribution of all stakeholders. To achieve competitiveness, new concepts have been developed like: implementing integrated quality management and developing planning destination management and sustainable destinations.

The planner has an enormous task: "sharing or reserving information, stimulating or discouraging public participation, urban planners can nurture collective hope or deepen citizen's resignation". Planners and planning can legitimately be concerned with healthcare, social issues, education, as well as more traditional land use affairs [47].

As the Syrian political system is not open to change or adjustment at this moment, the following suggestions regarding tourism have been derived from this study for future consideration:

First, urban and regional planning should establish more competitive, transparent, open, and comprehensive procedures. Excluding specially protected projects, all urban and regional planning for the upcoming 20-50 years should exist in a transparent market which will accept all urban planners and architectures who are interested in the process.

Second, free speech in tourism planning should be enabled and encouraged via formal hearings, the internet, public exhibitions, and other venues, thereby involving maximum public input to ensure the reliability and durability of planning. The planning process should be open to all social sectors rather than only those seeking profit.

Third, a transparent supervision system in urban and regional planning should be implemented and strictly enforced. Annual or periodic reviews of urban planning projects and relevant data should be published via the internet, along with other media and formal presentations. The administration should be advised by representatives across the sociopolitical spectrum. Through this monitoring system, tourism planning and development can be steered in the right direction to obtain the optimum results. 


\section{THE PROPOSED TOURISM STRATEGY IN THE SYRIAN COASTAL REGION}

To achieve consistency in decisions and guidelines at various levels of management and administration, the considerations of sustainable development must be obviously recognized by all players, and this demands appropriate communication channels[45]. Tourism planning represents the overall vision and economic goals for an area and allows for the implementation of a development roadmap for the coming years. A tourism plan should cover 3 to 5 years and strategic plan extend to 10 to 15 years and be flexible enough to allow implementation of new opportunities as they arise (Fig. 1). The planning process should define the ideal outcomes from tourism development. The plan should describe actions in a manner that allows for accurate implementation, creates discussion, and obtains the acceptance of stakeholders such:

1. Determine the business situation of the past, present, and future.

2. Identify opportunities related to tourism, and problems facing the community or sector.

3. Set specific and realistic business objectives.

4. Identify the strategies and tactics necessary to achieve the objectives.

5. Set a timetable and assign responsibilities for program implementation.

6. Develop monitoring and auditing methods to assess the effectiveness of programs for their specific purposes.

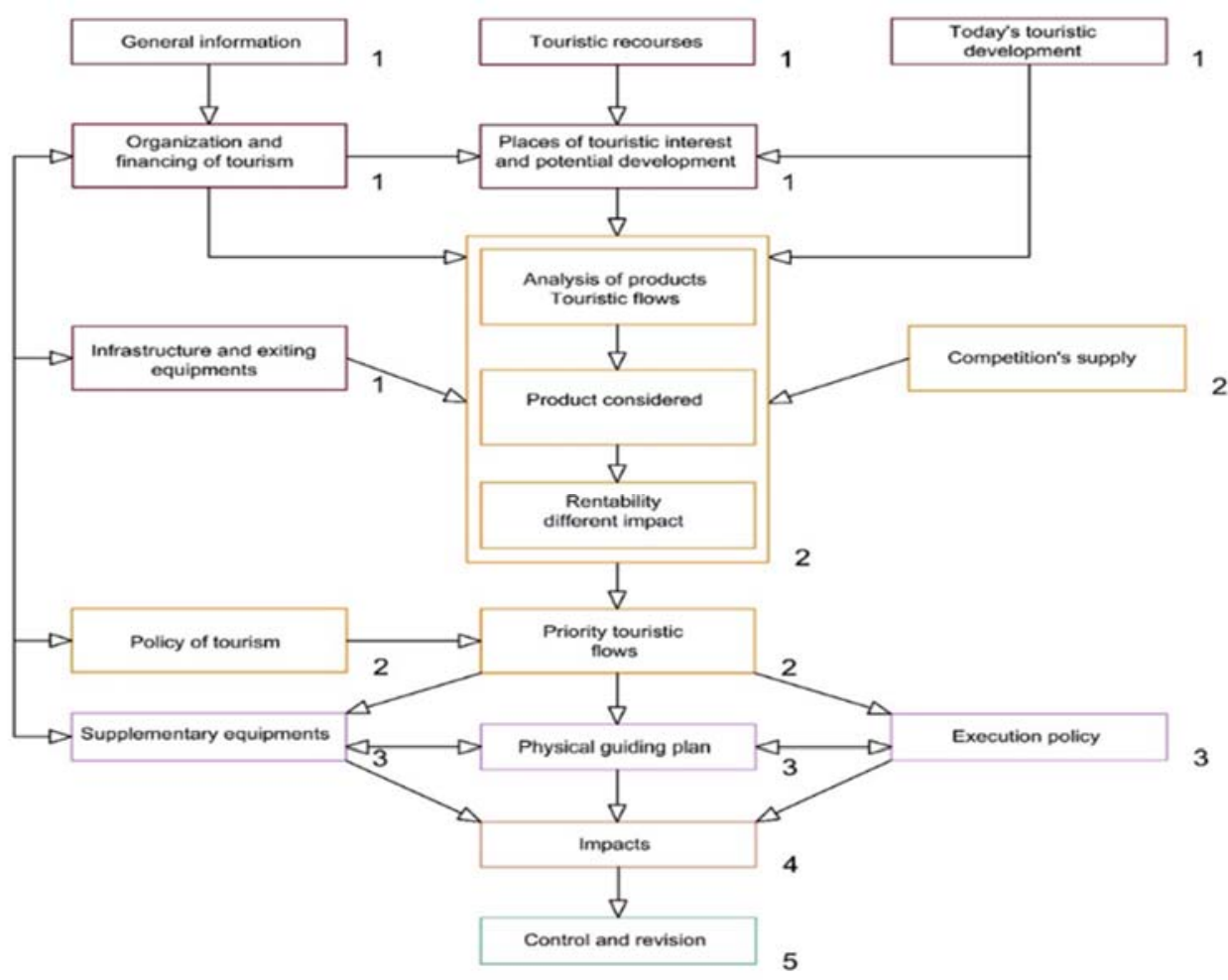

Figure 1: Model of the suggested Strategic Planning process of regional tourism development for the Syrian coastal region. (Source: Modified by author.) 
It is necessary to think of the planning process as a recurring cycle; experiences will determine how to adjust different segments. This knowledge can be incorporated into the successive plan as the situation evolves over time. The tourism sector plays an important role in sustainable development, such as by motivating infrastructure investment, and its benefits flow into other sectors. When implementing tourism projects, the broader impact of such activities must be estimated, especially regarding natural resource depletion/damage and unstable seasonal employment. Government regulators should be aware that large-scale tourism can affect the quality of life of local residents and damage environmental resources such as wildlife and nature reserves. The pressure by investors in sensitive areas must be controlled by enforceable restrictive land use policies [49].

To sum up, the following are practical steps to upgrade the development of tourism in the Syrian coastal region, as inspired by the Chinese experience. Tourist authorities on the coast of Syria should pay attention to the following points (see Figs 2-7):

1. Review the tourism potential in the region and formulate attractive and high-quality products which meet the tourism demands. And diversify the types of tourism products, targeting new tourist markets and further developing existing ones.

2. Establish and strengthen the infrastructure, which is essential when creating tourist facilities. And develop methods to access and update border crossings and tourist service centers.

3. Expand Khmeimim airport and develop a mechanism to realign it to tourism (such as increased international flights and more charter flights between provinces).

4. Organize interior and exterior marine tours and prepare tourist areas at the harbors in Ras al-Bassit, Jableh, Baniyas and Hamidiya. And create tourist zones and modern passenger terminals separated from commercial ports in Latakia and Tartus.

5. Employ scientific methods for more suitable, attractive, and economical land-use systems while preserving historical influence and guaranteeing sustainability.

6. Invest in archaeologically and historically significant areas, improve the quality of services in archaeological and cultural sites. And create landscaped gardens around archaeological sites with functional service kiosks and toilet facilities. And also set up tourism management systems at archaeological sites and improve lighting in these sites, as well as offering sound and light shows.

7. Develop mountain tourism and ensure sustainability according to international standards. Encourage ecotourism and exploratory tourism, providing the necessary needs and equipment required for these specialties. And establish and equip zones for camping and hiking in appropriate locations such as forests and lakeshores, with an emphasis on cleanliness and fire safety.

8. Achieve a balance of tourism investment between the mountains and the coast. And create integrated tourism projects between the coastal and the mountain regions and provide facilities that encourage balanced, sustainable tourism development.

9. Give particular attention to group trips, university-sponsored outings, and youth organizations.

10. Establish a zoo demonstrating integrated environmental patterns (Vital diversity).

11. Encourage religious tourism.

12. Encourage investment in projects such as water sports and cable cars.

13. Build replica towns with the features of an ancient Phoenician city and establish markets for the handmade products inspired by life in Ugarit and Amrit.

14. Hold an exposition of marine tourism on the Syrian coast and invite representatives from Mediterranean countries, appropriate organizations, and travel agencies. 
15. Activate sports attractions in Latakia to position it as a versatile cultural area throughout the year. Provide multi-purpose halls and outdoor cinemas and reorganize the green zones.

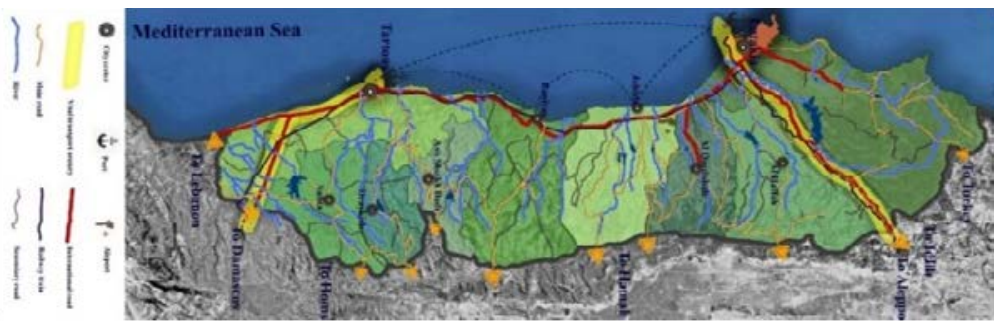

Figure 2: Transportation. (Source: Google maps edited by author.)

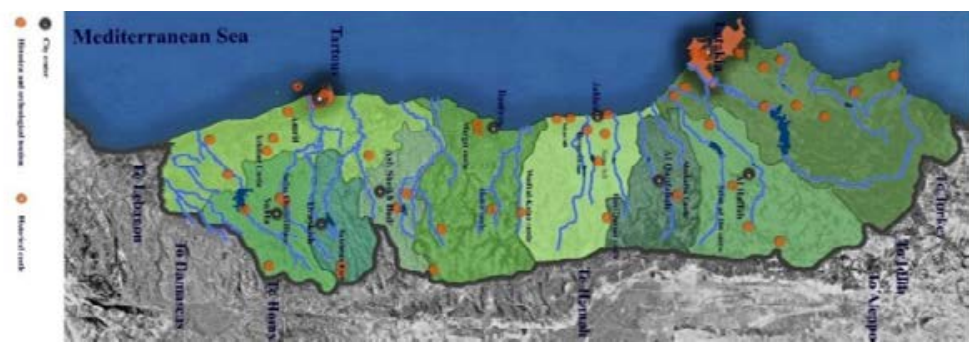

Figure 3: Archaeological and historical sites. (Source: Google maps edited by author.)

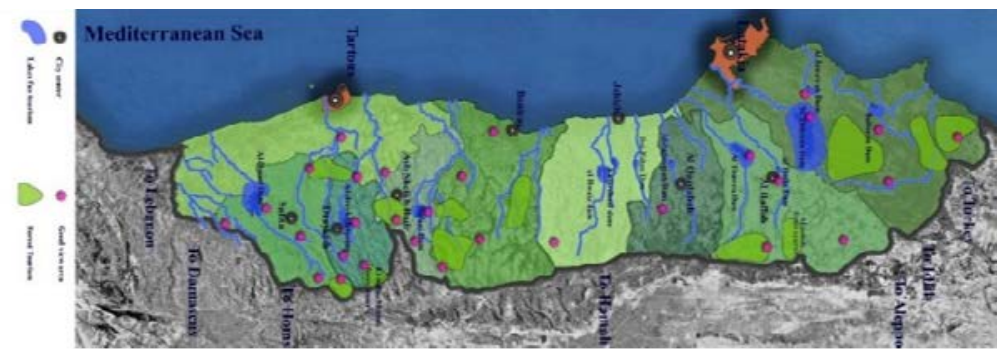

Figure 4: Natural tourist areas. (Source: Google maps edited by author.)

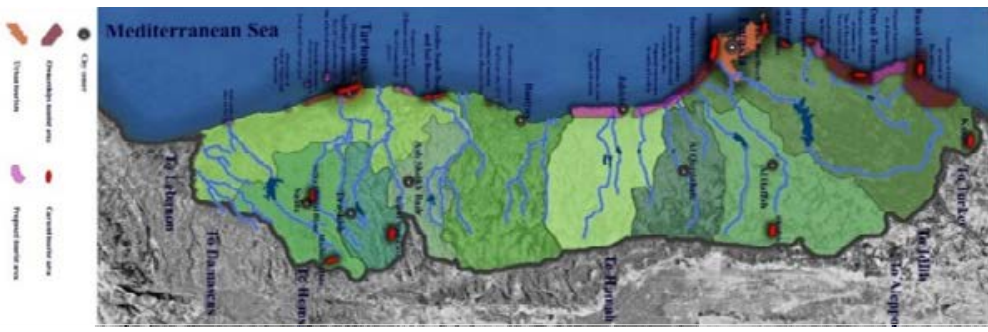

Figure 5: Existing and proposed tourist areas. (Source: Google maps edited by author.) 


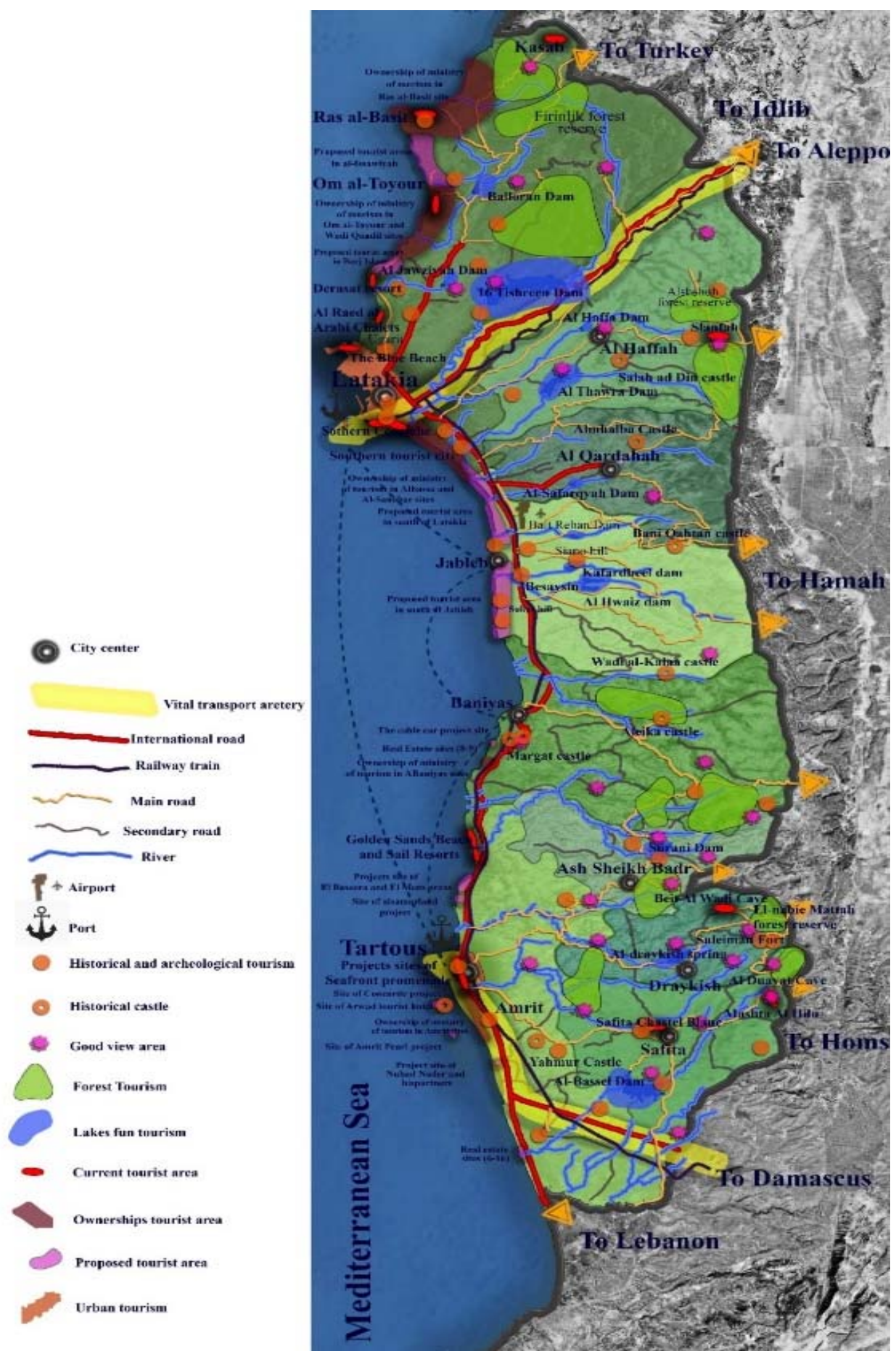

Figure 6: The proposed touristic strategy of the regional planning study. (Source: Google maps, edited by author.) 


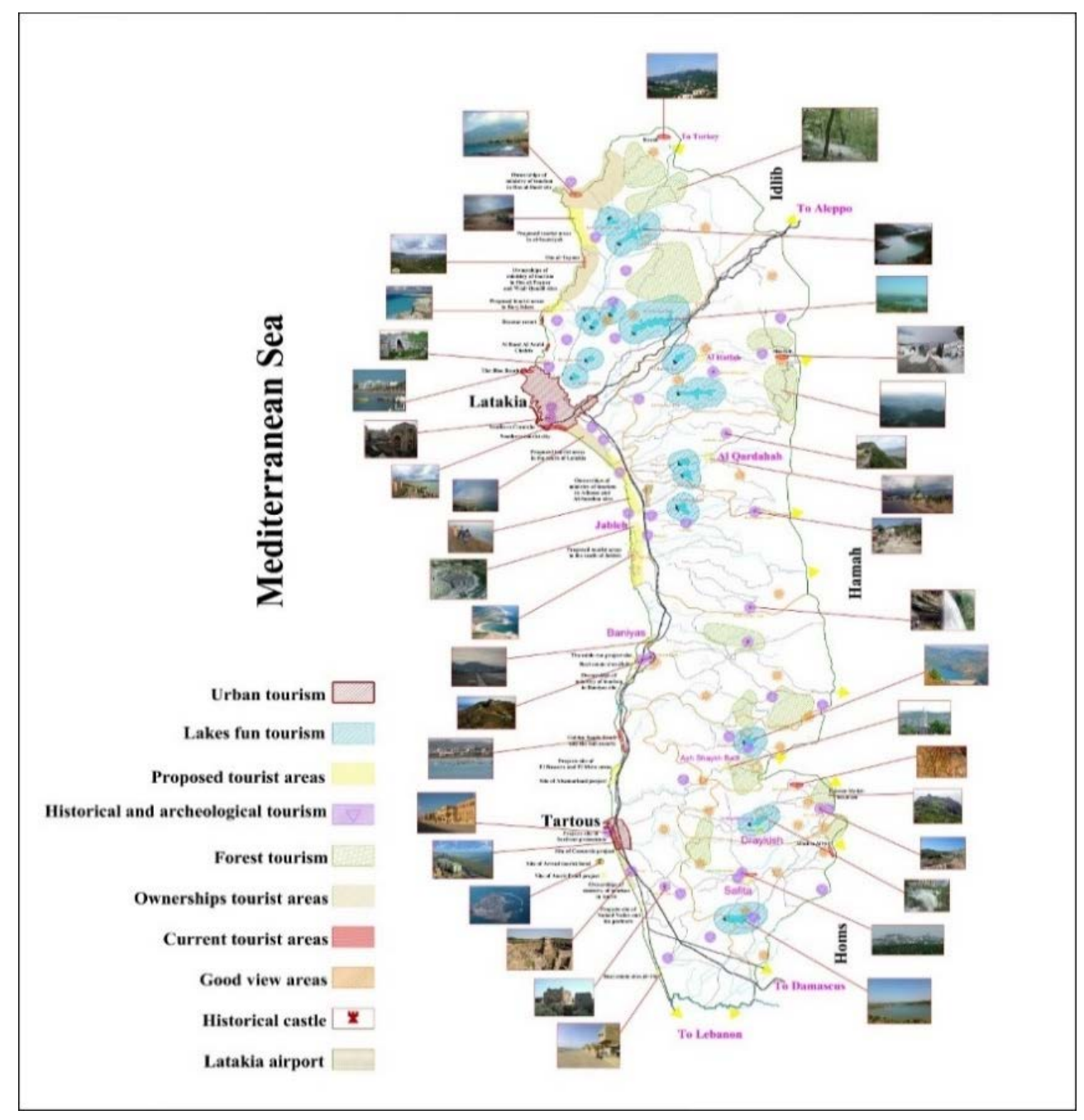

Figure 7: Syrian coastal region sightseeing map. (Source: amended by the author.)

It has become clear that the expansion of tourism markets and their increase, or the growth of the overall tourism industry, which is expected to advance in the coming decades as never before, as well as the establishment of numerous and more substantial tourist destinations, will have enormous effects on identity, culture and economy as well as on the physical environment. Spatial planning can, therefore, be used as a tool for coordinating economic and social development by protecting the cultural and natural environment and preventing environmental problems at the same time. The challenge is planning to ensure the development of balanced regional actions and to guarantee the effective use of limited land resources and the balanced use of resources, such as landscape resources, natural resources, air, soil, and water. Since spatial planning is of a long-term nature, it also can include significant basics for the sustainability area. Accordingly, the use of spatial planning to 
enhance and promote sustainable development includes more concepts of protection and development as complementary, rather than contradictory, components.

It is also essential to consider the integrating of sectors through spatial planning (crossborder cooperation, regional planning and sustainable urban development, business development, transportation, and biodiversity). Development of planning tools, involving democratic and public participation, must be done to encourage sustainable development in the Syrian coastal region[46]. Sustainable tourism development must be a central element for the strategic development of tourist destinations. It is in demand, to appropriately distribute the sustainable development of tourist resorts and destinations appropriately, at the same time to deal with the risks which may arise, related to overcrowding, that can lead to the unsustainable development of the most attractive and visited tourist spots. Which would negatively affect the possibility of transforming the Syrian coastal region into a leading tourist destination after the war.

In the case of the Syrian coastal region, negative factors could be overcome if the reasons for the success of Hainan were emulated. This hope could be driven by the substantial assets and potential of the Syrian coastal region. Resources for promoting and marketing Hainan, including the Hainan Tourism agency and its website, are essential factors in the island's success. Such resources are what the Syrian coast lacks presently, and which could be a key factor in turning the Syrian coastal region into a leading tourist destination after the war.

\section{ACKNOWLEDGEMENTS}

Many thanks to the Syrian Ministry of Higher Education, Tishreen University, Chinese Scholarships Council (CSC) and Chongqing University for offering me the financial, academic and technical support to pursue my study in Faculty of Architecture and Urban Planning in Chongqing University. I am very grateful to Professor Peifeng Yang for his generous and insightful supervision during my research and to Professor Tarek Barakat for the interviews and materials provided. Also, to the Syrian Ministry of Tourism, Syrian Regional Planning Commission and Hainan Government for the materials and interviews regarding Tourism and Regional Planning issues. This study was supported by the Chongqing Social Science Planning General Project 2016 (Grant No. 2016YBJJ031).

\section{REFERENCES}

[1] Morgan, N. \& Pritchard, A., Destination Branding: Creating the Unique, Oxford: Elsevier, 2002, 2004.

[2] Angeloni, S., The strategic plan for tourism development in Italy, Economia. Seria Management, 16(1), p. 107, 2013.

[3] Lamb, A., Tourism development and planning in Australia: The need for a national strategy, International Journal of Hospitality Management, 7(4), pp. 353-361, 1988.

[4] Angeloni, S., Destination Italy, Milano-Torino: Pearson Italia S.p.A., 2012, p. 113.

[5] Seidahmetov, M., Aidarova, A., Abishov, N., Dosmuratova, E. \& Kulanova, D., Problems and perspectives of development of tourism in the period of market economy (case republic of Kazakhstan). Procedia-Social and Behavioral Sciences, 143, p. 251-255, 2014.

[6] Gilbert, D., Strategic marketing planning for national tourism. The Tourist Review, 45(1), pp. 18-27, 1990. DOI: 10.1108/eb058038.

[7] Ritchie, J.R.B. \& Crouch, G.I., The Competitive Destination: A Sustainable Tourism Perspective, CABI Pub: New York, 2003. 
[8] Heath, E., Towards a model to enhance destination competitiveness: A Southern African perspective. Journal of Hospitality and Tourism Management, 10(2), pp. 124$141,2002$.

[9] The Authority on World Travel \& Tourism, Travel \& Tourism Economic Impact 2015 WORLD, World Travel \& Tourism Council (WTTC), London, 2015.

[10] Bertucci, G., Strengthening Local Governance in Tourism-Driven Economies, statement prepared for the International Colloquium on Regional Governance, 2002. Online. www.unpan.org.

[11] Delise, P.E., Sustainability \& Social Responsibility: Pacific Asia Travel Association (PATA). Online. http://sustain.pata.org/tourist-activity-as-sustainable-regionaldevelopment-instrument/. Accessed on: 6 Feb. 2015.

[12] Muhammad, E., Urban Tourism and Strategic Planning: An Integrated Study of Alexandria and Barcelona, UNICA Euromaster in Urban Studies, 4Cities, 2011.

[13] Inskeep, E., Tourism Planning: An Integrated and Sustainable Development Approach, Van Nostrand Reinhold: New York, 1991, pp. 70-71.

[14] The World Tourism Organization (WTO), National and Regional: Methodologies and Case Studies, Routledge: London, 1994.

[15] Lai, K., Li, Y. \& Feng, X., Gap between tourism planning and implementation: A case of China. Tourism Management, 27(6), pp. 1171-1180, 2006.

DOI: 10.1016/j.tourman.2005.11.009.

[16] Cooper, C., Wanhill, S., Fletcher, J., Gilbert, D. \& Fyall, A., Tourism: Principles and Practice, Longman Group: London, 1993.

[17] Gunn, C.A., Tourism Planning: Basics, Concepts, Cases, 4th ed., Routledge: New York, 2002.

[18] Mclntosh, R.W, Goeldner, C.R. \& Ritchie, J.R.B., Tourism: Principles, Practices, Philosophies, Wiley: New York, 1995.

[19] Shepherd, R., Tourism Principles and Practice, Longman: Harlow, 1998.

[20] Veal, A., Leisure and Tourism Policy and Planning, 2nd ed., CABI Publishing: New York: 2002.

[21] Burns, P.M., Tourism planning: A third way? Annals of Tourism Research, 31(1), pp. 24-43, 2004.

[22] Tosun, C. \& Jenkins, C., Regional planning approaches to tourism development: The case of Turkey. Tourism Management, 17(7), pp. 519-531, 1996.

[23] Burnsa, P.M. \& Sancho, M.M., Local perceptions of tourism planning: The case of Cuéllar, Spain. Tourism Management, 24(3), pp. 331-339, 2003.

[24] Lew, A.A., Tourism planning and traditional urban planning theory- the planner as an agent of social. Leisure/Loisir, 31(2), pp. 383-391, 2007.

DOI: $10.1080 / 14927713.2007 .9651387$.

[25] Vollmer, D., Developing Leadership in Your Drycleaning Business (Conclusion). Online. https://americandrycleaner.com/articles/developing-leadership-yourdrycleaning-business-conclusion. Accessed on: 29 May 2014.

[26] Integrated Coastal Zone Management (ICZM), Maritime Spatial Planning (MSP), Exploring the potential of maritime spatial planning in the Mediterranean Sea: Country reports. I. SYRIA, European Commission study, Brussels, Luxembourg, 2011.

[27] UNEP/MAP-METAP SMAP III Project, Towards a Strategy for Syria's Coast - ICZM Policy Background, SMAP III/2008/PB.S Priority Actions Programme Regional Activity Centre, Split, 2008.

[28] Ministry of Transportation in The Syrian Arab Republic, The reality and prospects of transportation in Syria (in Arabic), Damascus, 2012. 
[29] Priority Actions Programme Regional Activity Centre (PAP/RAC), Improving Coastal Land Degradation Monitoring in Lebanon and Syria: Country Report Syria, 2004 United Nations Environment Programme Mediterranean Action Plan Priority Actions Programme, Split, 2004.

[30] Ministry of Tourism in The Syrian Arab Republic, The touristic study of regional planning project of Lattakia-Tartus (in Arabic), Damascus, 2010.

[31] UNEP/MAP-METAP SMAP III Project, Syria's Coastal Zone and its Desired Integrated Management-Proposed Vision and Policy, SMAP III/2009/ICZMNPR/ENG Priority Actions Programme Regional Activity Centre, Split, 2009.

[32] Markovic, M., Satta, A., Skaricic, Z. \& Trumbic, I., Sustainable Coastal Tourism/an integrated planning and management approach, United Nations Environment Programme, 2009, Paris, 2009.

[33] PAP/RAC, UNEP/MAP/PAP. Online. www.pap-thecoastcentre.org/pdfs/ Protocol_publikacija_May09.pdf. Accessed on: 21 Jan. 2008.

[34] Travel China Guide, Travel China Guide. Online. Available: www.travelchinaguide.com/intro/geography/. Accessed on: 9 Sep. 2013.

[35] Falkenheim, V.C., Hainan. Online. www.britannica.com/place/Hainan. Accessed on: 24 Feb. 2014.

[36] JICA, Hainan Development Project (Highway) (I) (II)-Hainan East Expressway Expansion Project, Waseda Research Institute Corp, Tokyo, 2008.

[37] Chinatravel.com, Hainan Transport. Online. www.chinatravel.com/hainan/ transport.htm. Accessed on: 9 Jan. 2013.

[38] Platinum Broking Company Limited, Hainan Property Guide, 2013 Platinum Broking Company Limited, Hong Kong, 2013.

[39] Wang, J. \& Liu, Y., Tourism-led land-use changes and their environmental effects in the southern coastal region of Hainan Island, China. Journal of Coastal Research, 290(5), pp. 1118-1125, 2013. DOI: 10.2112/jcoastres-d-12-00039.1.

[40] Tse, Y.C.H., Feasibility Study on Hainan Project-Case Study for Licon (Holdings) Limited, Tampere University of Applied Sciences: Tampere, 2010.

[41] The Authority on World Travel \& Tourism, Hainan Travel \& Tourism Development Potential 2011-2021, World Travel \& Tourism Council (WTTC): London, 2012.

[42] Hainan Government, "Home>>TopNews: The official website of the Hainan Government." Online. http://en.hainan.gov.cn/englishgov/TopNews/201002/ t20100212 42651.html. Accessed on: 12 Feb. 2010.

[43] Goulard, S., Mediterranean Islands and the challenge of innovation: Learning from the case of the chinese province of Hainan. Presented at 2nd International Conference on Human and Social Sciences, ICHSS 2012, 5, Rome, 2012.

[44] Niezgoda, A., Problems of implementing sustainable tourism in Poland. The Poznań University of Economics, 4(1), pp. 30-42, 2004.

[45] Nowacki, M., Anioł, J.K., Królikowska, K., Rak, M.P. \& Awedyk, M., Strategic planning for sustainable tourism development in Poland. International Journal of Sustainable Development \& World Ecology, 25(6), pp. 562-567, 2018. DOI: 10.1080/13504509.2018.1432513.

[46] Risteskia, M., Kocevskia, J. \& Arnaudov, K., Spatial planning and sustainable tourism as basis for developing competitive tourist destinations. Procedia-Social and Behavioral Sciences, 44, pp. 375-386, 2012. DOI: 10.1016/j.sbspro.2012.05.042.

[47] Erixon, R.X., Sanya-Chinese Hawaii-through one phoenix to see the big picture, KTH Architecture and the Built Environment, Stockholm, 2012. 
556 Sustainable Development and Planning X

[48] Costa, C., An emerging tourism planning paradigm? A comparative analysis between town and tourism planning. International Journal of Tourism Research, 3(6), pp. 425441, 2001. DOI: $10.1002 /$ jtr.277.

[49] Neves, P., Tourism Towards Sustainable Regional Development, Kungliga Tekniska Högskolan: Stockholm, 2006.

[50] Regional Planning Commission, National Framework of Regional Planning, Damascus, 2012.

[51] Tourism Directorate in Latakia \& Tartus, Tourism Investment, Latakia \& Tartus, 2011.

[52] Sassila, R., Analytical Study of the Syrian Coastal Zone, Damascus, 2009.

[53] Ministry of Local Administration and Environment-Lattakia \& Tartus Regional Planning Project, The touristic study of regional planning project of Lattakia \& Tartus, Directorate of Decision Support \& Regional Planning, Lattakia \& Tartus, 2010. 